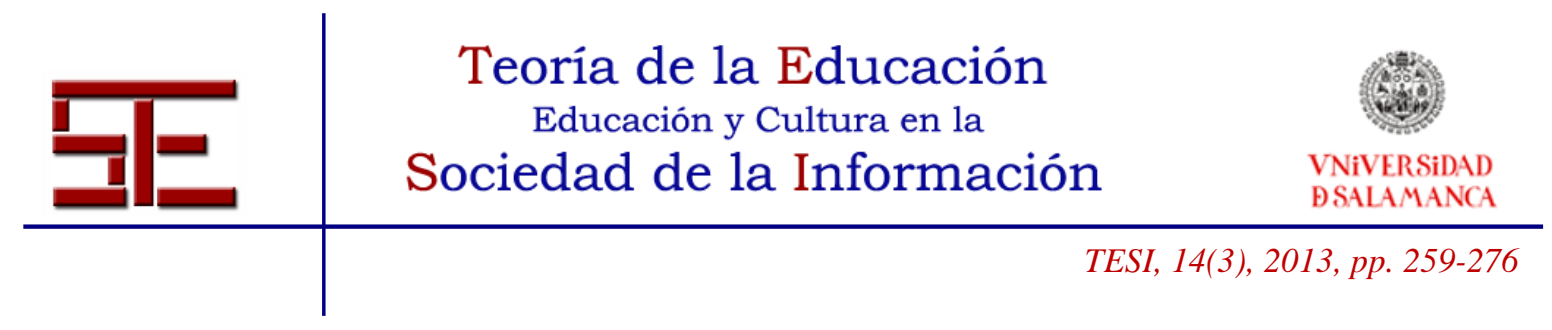

\title{
LA PERCEPCIÓN DEL ALUMNADO SOBRE LAS COMPETENCIAS DOCENTES DEL PROFESORADO DE LA RAMA DE CIENCIAS SOCIALES Y JURÍDICAS DE LA UNIVERSITAT DE VALÈNCIA
}

Resumen: En el presente trabajo se presentan los datos de una investigación realizada en la Universidad de Valencia en la que se analiza la percepción del alumnado sobre las competencias docentes del profesorado del área de Ciencias Sociales y Jurídicas. En el estudio participaron un total de 389 estudiantes universitarios de 10 titulaciones diferentes de la Universitat de València. En general, las 32 competencias son valoradas por los sujetos de la muestra como muy importantes en el proceso de enseñanza/aprendizaje. El alumnado valora las competencias personales como las más importantes, seguidas de las científicas, las metodológicas y las sociales.

Globalmente las dos competencias más valoradas hacen referencia al trato correcto y respetuoso con el alumnado, así como a la creación de un clima de aula basado en el diálogo y la comunicación. Este dato es una constante que se repite en todas las titulaciones analizadas, con pequeñas variaciones. Las competencias menos valoradas son "Mantener una imagen personal cuidada" y "Estar al día de las nuevas tecnologías de la información y la comunicación".

Palabras clave: Competencias, profesorado universitario, docencia universitaria, percepción del alumnado 


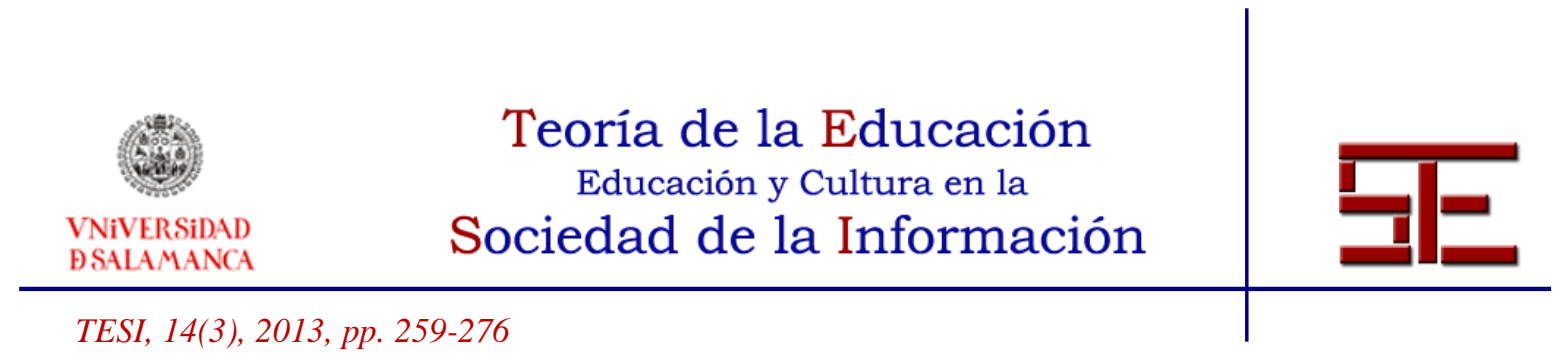

\section{STUDENTS' PERCEPTION ON TEACHING COMPETENCES OF TEACHERS OF THE BRANCH OF SOCIAL SCIENCE AND LAW OF THE UNIVERSITY OF VALENCIA}

Abstract: This paper presents data from research conducted at the University of Valencia in order to analyse students' perception on teaching competences of teachers in the area of Social and legal Sciences. The study included a total of 389 university students from 10 different degrees of the University of Valencia. In general, the subjects in the sample rated the 32 competencies as very important in the teaching / learning process. Students assess personal skills as the most important competences, followed by scientific, methodological and social ones.

Overall the two most valued competences refer to "the proper and respectful treatment of students", as well as "creating a classroom atmosphere based on dialogue and communication". This data is a constant that is repeated in all degrees tested, with minor variations. The competences which are less valued are "Maintaining a careful personal image" and "keep update on new information and communication technologies".

Key words: Competences, university teachers, university teaching, students' perception.

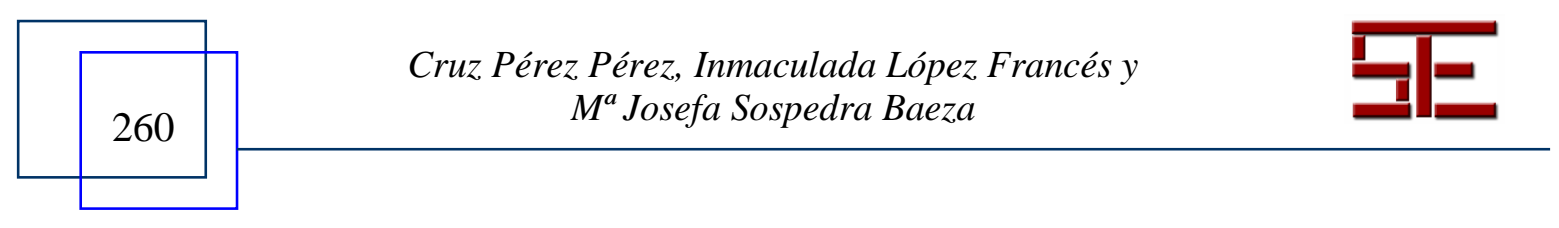




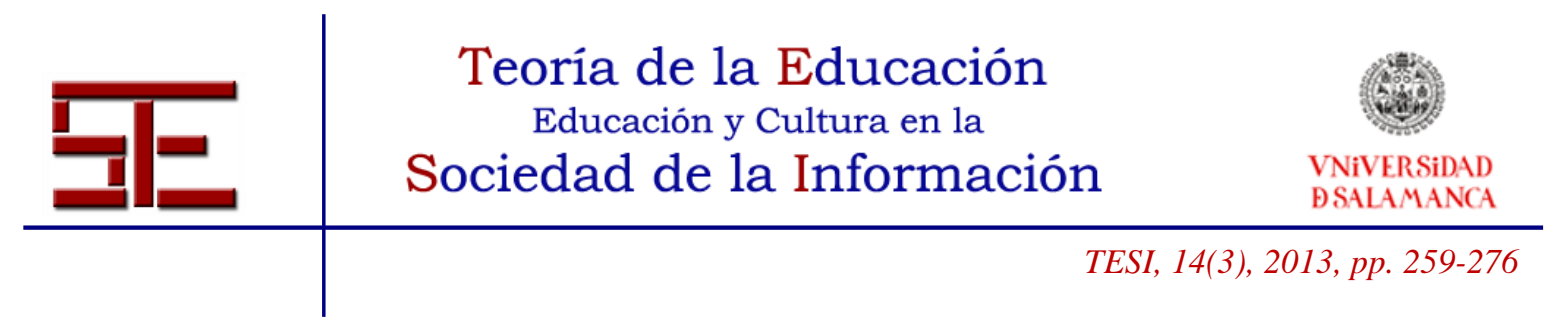

\title{
LA PERCEPCIÓN DEL ALUMNADO SOBRE LAS COMPETENCIAS DOCENTES DEL PROFESORADO DE LA RAMA DE CIENCIAS SOCIALES Y JURÍDICAS DE LA UNIVERSITAT DE VALÈNCIA ${ }^{\mathbf{1}}$
}

Fecha de recepción: 19/05/2013; fecha de aceptación: 08/07/2013; fecha de publicación: 30/11/2013

\author{
Cruz Pérez Pérez \\ cruz.perez@uv.es \\ Universitat de València \\ Inmaculada López Francés \\ inmaculada.lopez-frances@uv.es \\ Universitat de València \\ $\mathrm{M}^{\mathrm{a}}$ Josefa Sospedra Baeza \\ maria.jose.sospedra@uv.es \\ Universitat de València
}

\section{EL CONCEPTO DE COMPETENCIA DEL QUE PARTIMOS}

En el ámbito educativo existe una tendencia a identificar las competencias con el saber hacer. Esta perspectiva, entiende las competencias como capacidades, es decir, como un sistema especializado de recursos cognitivos y conocimientos necesarios para realizar un desempeño.

En este trabajo no nos identificamos con esta concepción, ni la consideramos un aporte a la teoría y práctica educativa. No encontramos diferencias sustanciales entre la competencia entendida como capacidad y otros conceptos como capacidades cognitivas, aptitudes o procedimientos. La competencia entendida desde esta perspectiva sólo aportaría a la educación, a nuestro juicio, la dimensión del saber hacer, esto es, la función aplicada del conocimiento, que es en sí misma valiosa, necesaria, pero no suficiente para la educación basada en competencias. De la misma manera, entendemos que "la competencia no existe por sí sola, independientemente de un sujeto que la posee y de la que no puede disociarse. Lo que existe realmente son personas más o menos competentes" (Le Boterf, 2000,120).

La competencia entendida como capacidad partiría, a nuestro juicio, de una visión reducida del ser humano, e incluso de lo que éste puede hacer. Corre el riesgo en su aplicación de reducir el saber a aquellos conocimientos que permiten un saber hacer inmediato (González y otros, 2011). Quienes entienden las competencias de este modo podrían estar comprometidos con un concepto pobre de la calidad y la equidad en la educación. La calidad estaría entendida como la consecución de logros de aprendizaje perfectamente observables y cuantificables, que permitan la clasificación y selección de

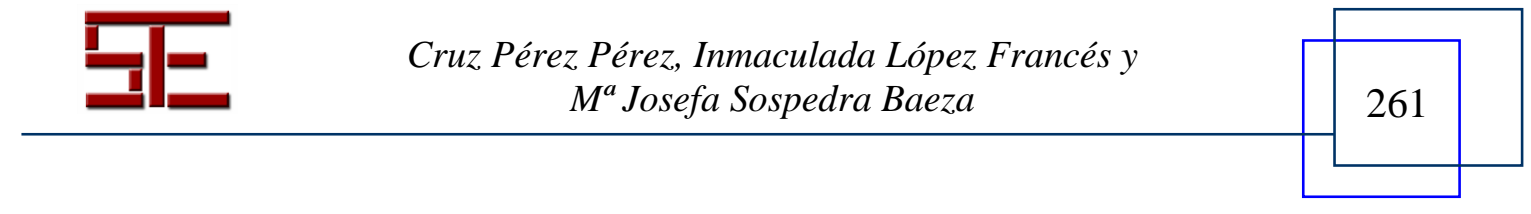




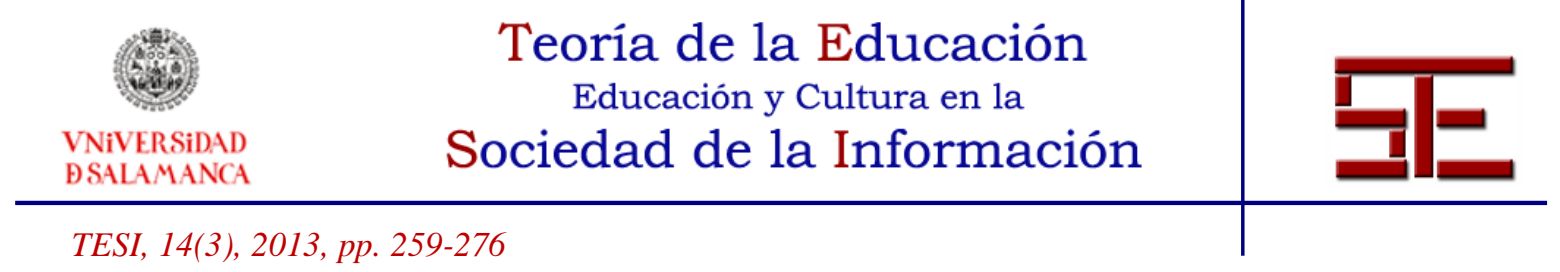

los sujetos, y no como la oportunidad que concede el sistema educativo para que cada alumno logre desarrollar sus máximas potencialidades y construya un proyecto de vida óptimo. Igualmente, entenderían la equidad como la preocupación por garantizar una serie de logros comunes a todos los alumnos de un determinado nivel educativo (Sarramona, 2004) cuando, el objetivo fundamental de la equidad en la educación, en una sociedad democrática, debe ser el reconocimiento de la diversidad existente entre los estudiantes, para proponer desde allí los apoyos diferenciales a fin de asegurar que los objetivos se logren de manera equiparable para todos. En fin, creemos que desde esta perspectiva el mundo productivo es el ganador, ya que formar competencias indudablemente será un indicador de éxito.

Una segunda perspectiva en torno al concepto de competencia, entiende el modelo competencia-desempeño desde una visión más integradora. Las competencias en educación se refieren a los dominios de carácter complejo, que adquiere un individuo por acción del aprendizaje y que manifiesta a través de unos desempeños, en el marco de la solución de problemas. Desde esta concepción, las competencias no se entienden como capacidades en sí mismas, sino como aprendizajes individuales, variables que requieren de recursos individuales y del contexto (aptitudes, rasgos de personalidad, conocimientos, experiencias, actitudes, valores, redes de información, relaciones, necesidades, oportunidades) para su adquisición y actuación. Asimismo, no existe una única competencia, ni un único modo de expresarla, ni siquiera un mismo nivel de dominio, puesto que no todas las personas tenemos las mismas capacidades, aptitudes, rasgos de personalidad, experiencias y valores, ni tampoco tenemos la misma relación con el contexto.

Desde nuestro acercamiento particular a un concepto de las competencias en la educación, hemos intentado clarificar cuatro ideas fundamentales con las cuales nos sentimos identificados (Zabala y Arnau, 2007): 1. Las competencias son aprendizajes complejos que se manifiestan en desempeños y se adquieren y realizan gracias a la movilización que realiza la persona de sus recursos incorporados así como de los que le ofrece su entorno, para solucionar problemas en un contexto determinado. 2. Las competencias se adquieren en el marco de la solución de problemas y exigen para su formación tanto de los conocimientos como de las oportunidades de ejercitación. 3. Las competencias no son los conocimientos, ni las capacidades de una persona, como tampoco la aplicación de los conocimientos. Las competencias trascienden los saberes para convertirse en estrategias de actuación frente a situaciones concretas y en contextos determinados. 4. Las competencias son evaluables en la medida que se manifiestan en unos desempeños. Sin embargo, éstos no son un reflejo fiable de la competencia, ya que no podemos precisar a través de ellos el tipo de movilización de recursos que realiza el sujeto; de todas maneras ofrecen una idea de los recursos con que cuenta la persona y orientan futuras acciones educativas.

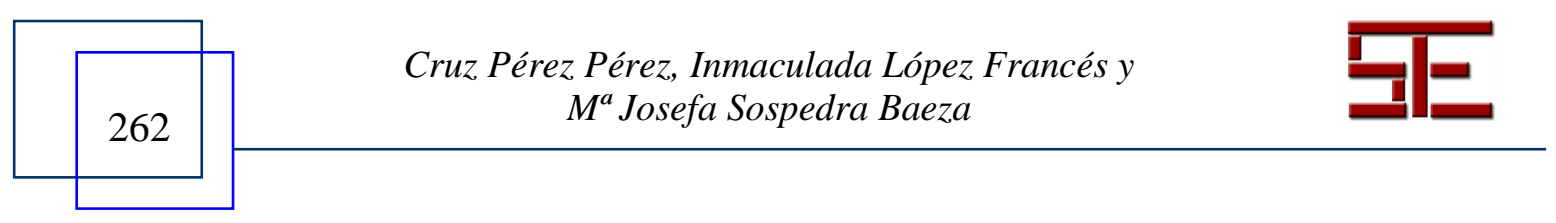




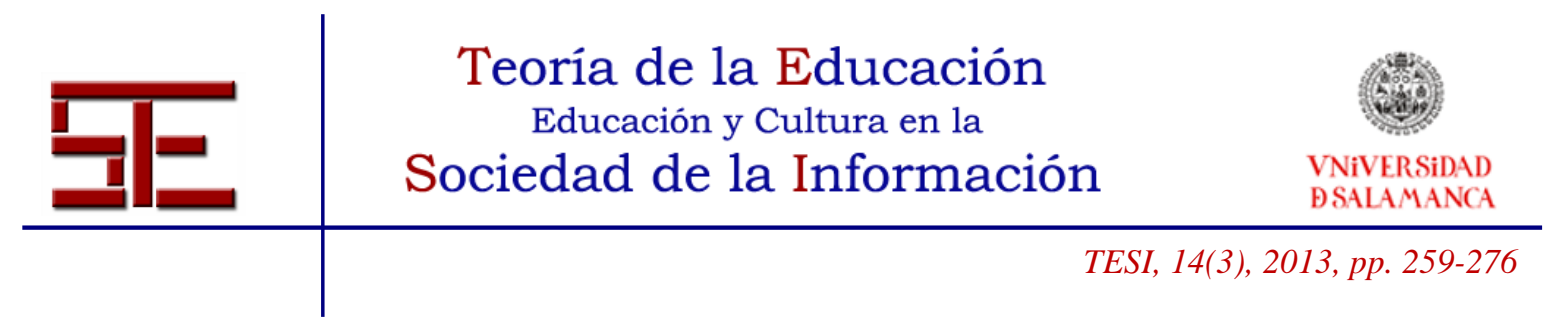

Trascendiendo las dos perspectivas sobre la educación basada en competencias que hemos ido comentando y analizando las posibilidades que ofrece (aprendizaje significativo para la vida, aprendizaje de habilidades y actitudes para seguir aprendiendo, aprendizaje contextual y en el marco de la resolución de problemas, aprendizaje flexible, aprendizaje que requiere el desarrollo de prerrequisitos cognitivos, procedimentales y actitudinales, aprendizaje demostrable a través de desempeños y en distintos grados, entre otros), podemos afirmar que educar por competencias constituye un reto de gruesa envergadura.

No se trata solamente de capacitar a los alumnos para el desempeño de una misión (oficio, labor concreta, meta específica), ni de conseguir la maestría (eficacia) en su realización. Educar por competencias requiere aprender a movilizar todas aquellas capacidades, aptitudes, rasgos de personalidad, actitudes, valores, así como conocer y comprender el contexto en el que se desenvuelve la persona para que, frente a un trabajo o misión, ponga en juego sus conocimientos, seleccione los procedimientos más adecuados para su realización y, a la vez, que su comportamiento sea satisfactorio. Dicho de otra manera, la formación de competencias requiere una visión integradora de la educación, una comprensión de sus últimos objetivos: aprender a conocer, aprender a hacer, aprender a vivir juntos y aprender a $\operatorname{ser}^{2}$ (Delors, 1996, 96-108).

Por otra parte, concebir las competencias como aprendizajes establece un vínculo entre las capacidades individuales, los conocimientos adquiridos, las misiones a llevar a cabo, los comportamientos puestos en práctica para hacerlo, y las cualidades necesarias para comportarse de manera satisfactoria; o lo que es igual, las competencias representan una relación entre el conocimiento declarativo, procedimental, las características individuales, las cualidades requeridas, el contexto en que se realiza y las exigencias propias de la misma misión (Rey, 2000). Entender las competencias de esta manera abre un espacio importante a la acción educativa: lo que se puede aprender, se puede enseñar, en tanto, el sistema educativo formal adquiere un papel protagónico en su consecución.

\section{INVESTIGACIONES SOBRE COMPETENCIAS DEL PROFESORADO}

La investigación sobre competencias docentes, tanto en niveles universitarios como no universitarios, ha sido intensa durante los últimos años, como consecuencia de la adaptación al nuevo escenario configurado por el EEES. En el contexto de la educación superior, algunas investigaciones se han centrado en determinar qué competencias son percibidas o atribuidas al profesorado universitario (Smith y Simpson, 1995; Tigelaar y otros, 2004). Otras líneas de investigación han analizado las competencias deseables para el profesor en la educación superior, con el objetivo de establecer las bases sobre las que llevar a cabo la formación del profesorado (González y Wagenaar, 2003; Yániz, 2008; Gilis et al., 2008) o la evaluación de la docencia (Roelofs y Sanders, 2007).

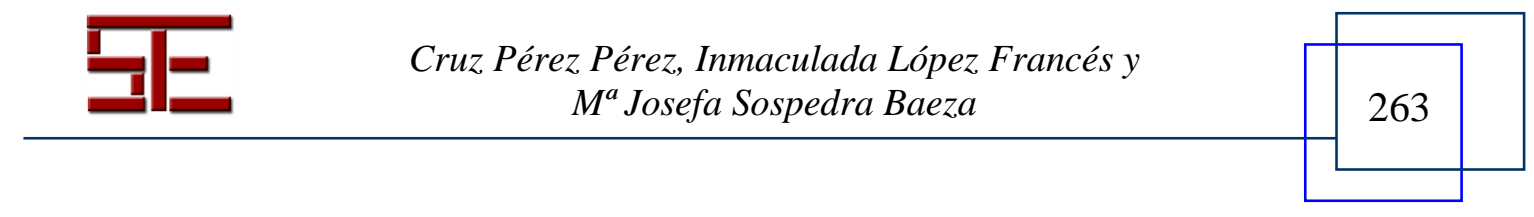




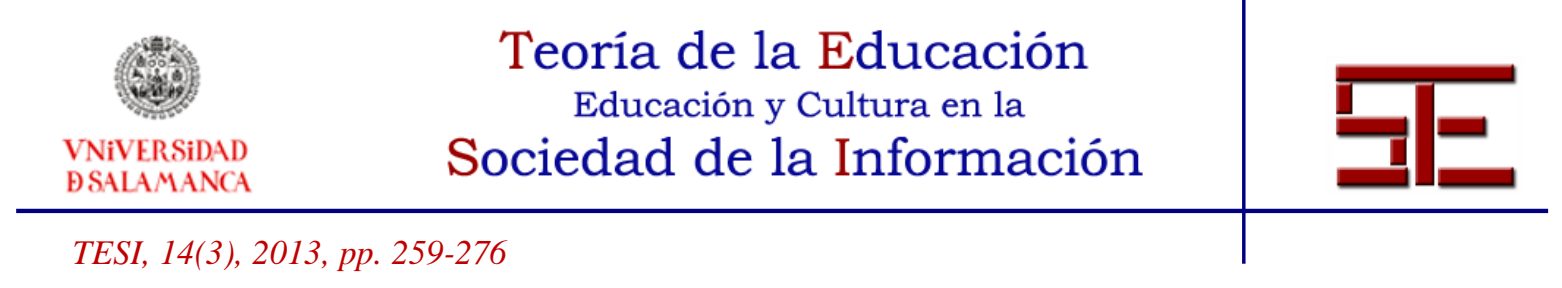

En el ámbito de nuestro país cabe destacar la investigación llevada a cabo en diversas universidades españolas (Rojo et al, 2009) en la que se tratan de identificar los perfiles y competencias docentes que podrían resultar más relevantes y útiles de cara a la docencia en el EEES. Los resultados de este trabajo concluyen que las competencias más valoradas son las que hacen referencia a la planificación de la docencia, al desarrollo de la docencia y a la evaluación. Entre ellas, se han incluido las que hacen referencia directa a elementos característicos del marco definido por el EEES, como son la importancia de desarrollar en el alumnado competencias académico-profesionales, conectar la teoría con la práctica, orientar y hacer un seguimiento del trabajo del alumnado, y favorecer su capacidad de aprendizaje autónomo.

También es bien conocida la investigación de Zabalza (2003), quien atribuye al profesorado universitario las siguientes competencias profesionales: planificar el proceso de enseñanza-aprendizaje, seleccionar y preparar los contenidos disciplinares, ofrecer informaciones y explicaciones comprensibles y bien organizadas, manejar las nuevas tecnologías, diseñar la metodología y organizar las actividades, comunicarse y relacionarse con los alumnos, tutorizar, evaluar, reflexionar e investigar sobre la enseñanza, identificarse con la institución y trabajar en equipo.

Otra línea de investigación sobre el tema es aquella que se centra en la evaluación del aprendizaje del alumnado universitario en función de las competencias adquiridas. Cabe destacar la investigación de la profesora $\mathrm{M}^{\mathrm{a}}$ Elena Cano ((2008) en la que se analizan las repercusiones que este nuevo enfoque genera sobre el trabajo del profesorado en general, y sobre la docencia en particular y en la que se concluye que si se cambia el modelo de evaluación se debe cambiar todo el proceso, pasando de una evaluación de los aprendizajes a una evaluación para los aprendizajes.

En esta línea, la investigación llevada a cabo en la Universidad de Barcelona (Ion y Cano, 2012) señala que una evaluación centrada en competencias, supone un cambio en las metodologías docentes del profesorado, lo cual implica la necesidad de llevar a cabo proceso de formación del profesorado en este ámbito.

\section{OBJETIVOS DE LA INVESTIGACIÓN}

1.Averiguar cuáles son las competencias docentes del profesorado que más valoran los alumnos de diferentes titulaciones de la rama de Ciencias Sociales y Jurídicas de la Universidad de Valencia.

2.Analizar estas competencias docentes en función de los cuatro grupos de competencias establecidos: competencias personales, sociales/participativas, metodológicas/técnicas y científicas.

3.Analizar si existen diferencias entre las competencias del profesorado que más valora el alumnado en función del género.

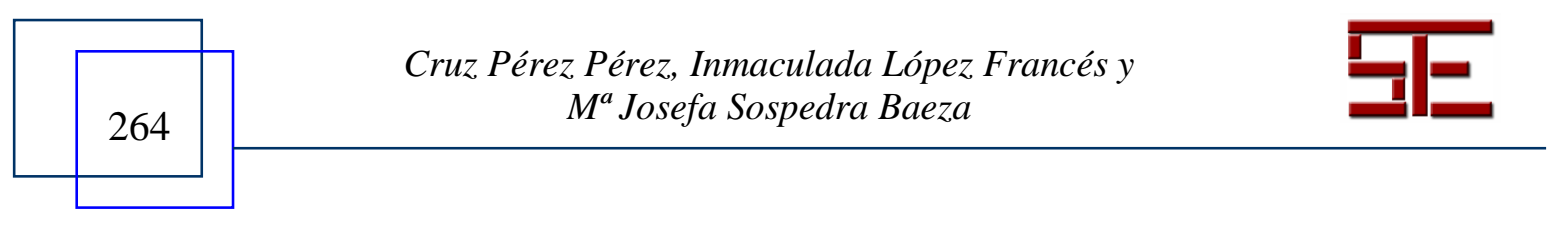




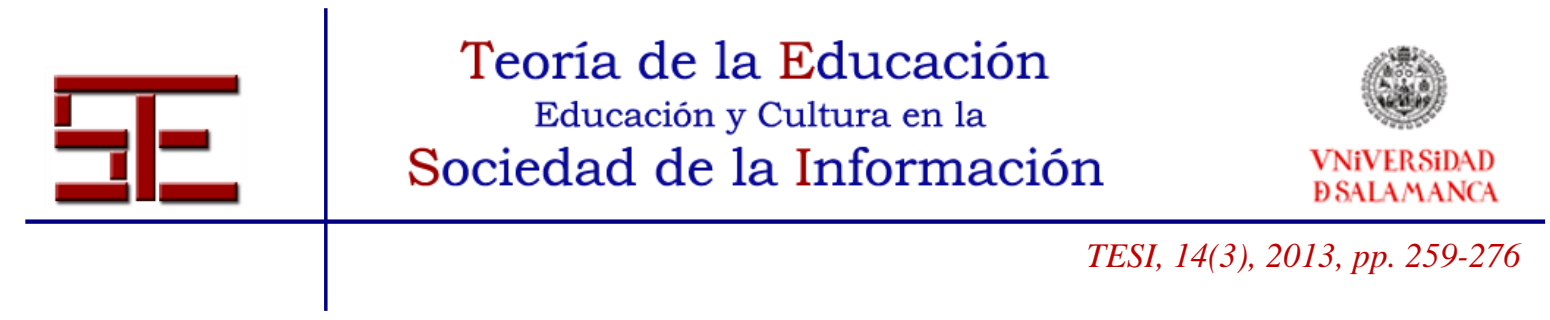

\section{EL INSTRUMENTO DE MEDIDA}

Para realizar esta investigación se utilizó el cuestionario de "Valoración de las competencias del profesorado universitario". Dicho cuestionario fue elaborado por el grupo de Innovación Educativa de la Universidad de Valencia de la titulación de Pedagogía (Pérez, et al, 2012), basándose en la agrupación de las competencias específicas que realiza la profesora Gemma Tribó para el profesorado de Educción Secundaria, pero adaptándolas a la especificidad de la docencia en la universidad (Tribó, 2008).

El cuestionario fue construido y validado en el contexto de la investigación financiada por la Universidad de Valencia "Docinvest", por el grupo de investigación sobre competencias profesionalizadoras de dicha universidad. La relación de los ítems del mismo aparece en los resultados de la tabla 1.

\section{RESULTADOS DE LA INVESTIGACIÓN}

\subsection{Descripción de la muestra, después de la depuración de los datos iniciales}

En el estudio participaron un total de 409 estudiantes universitarios de 10 titulaciones diferentes de la Universitat de València que quedaron reducidos a 389 tras la depuración de los datos. El $72.8 \%$ chicas y el $27.2 \%$ restante chicos con edades entre 18 y 55 años (media: 22.01; DT: 5,3).

Tabla 1. Relación de titulaciones y asignaturas que componen la muestra utilizada

\begin{tabular}{|l|l|l|}
\hline Titulación: & Asignatura & $\mathrm{n}$ \\
\hline Trabajo social & Derechos humanos & 29 \\
\hline & Derechos sociales & 28 \\
\hline Magisterio & E. Primaria: $\mathrm{H}^{\mathrm{a}}$ de la Escuela & 42 \\
\hline & E. Infantil: $\mathrm{H}^{\mathrm{a}}$ de la escuela & 11 \\
\hline Pedagogía & Filosofía de la educación & 21 \\
\hline & Análisis sistémicos & 13 \\
\hline & Educación Moral para la ciudadanía & 48 \\
\hline Educación social & Pedagogía social & 22 \\
\hline DADE (ADE +derecho) & Derecho procesal & 102 \\
\hline Derecho & Introducción al derecho procesal & 18 \\
\hline
\end{tabular}

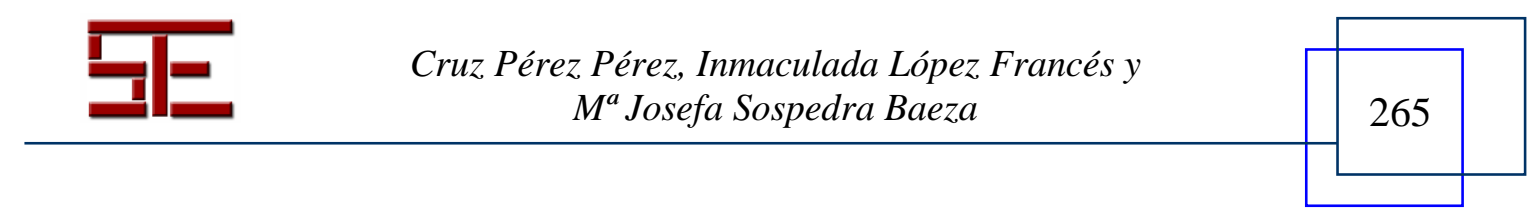




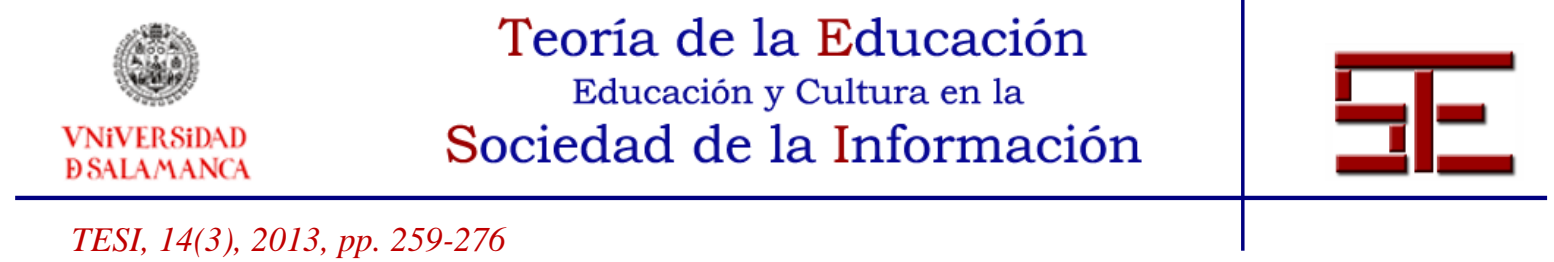

\begin{tabular}{|c|c|c|}
\hline $\begin{array}{l}\text { Mixto: Extensión } \\
\text { Universitaria }\end{array}$ & Educación para la paz & 15 \\
\hline \multirow{2}{*}{$\begin{array}{l}\text { Máster profesorado } \\
\text { secundaria }\end{array}$} & Procesos y contextos educativos (grupo A) & 27 \\
\hline & Procesos y contextos educativos (grupo B) & 13 \\
\hline Total & & 389 \\
\hline
\end{tabular}

El 26.22\% estudiantes de ADE y Derecho; el 21.08\% de Pedagogía; el $14.65 \%$ de Trabajo Social; el 10.80\% de Magisterio especialidad Educación Primaria; el 6.94\% de Máster de Secundaria A; el 5.66\% de Educación Social; el 4.63\% de Derecho; el 3.86\% de Mixto: Extensión Universitaria; el 3.34\% de Máster de Secundaria B y, el 2.83\% de Magisterio especialidad Educación Infantil.

\subsection{Resultados obtenidos}

\subsubsection{Resultados globales del total de la escala}

El cuestionario para la valoración de las competencias del profesorado consta de cuatro escalas de ocho ítems cada una de ellas con respuesta tipo likert de cinco puntos de anclaje. Por ello, en esta muestra, la puntuación máxima para cada ítem es de 1945 puntos y la mínima de 389. En general, todas las competencias son valoradas por los sujetos de la muestra como muy importantes en el proceso de enseñanza/aprendizaje (E/A).

En cuanto a la valoración otorgada por los sujetos de la muestra a cada uno de los ítems, independientemente de la escala (tabla 1), la competencia que consideran más relevante en el docente para el proceso de E/A es "Ser correcto y respetuoso en el trato con el alumnado" (1772 ptos.), seguida de "Fomentar un clima relacional de aula basado en el respeto al otro y en la libertad de expresión, utilizando constantemente el diálogo y la comunicación" (1734 ptos.).

En el polo opuesto, el ítem valorado como menos importante para el proceso de E/A ha sido "Mantener una imagen personal cuidada (vestuario, peluquería, etc.)" (1183 ptos.).

Tabla 2. Relación de ítems y valoración otorgada

\begin{tabular}{|l|c|}
\hline \multicolumn{1}{|c|}{ Ítem } & $\begin{array}{c}\text { Puntuac } \\
\text { ión }\end{array}$ \\
\hline CS/P: Mantener una imagen personal cuidada (vestuario, peluquería, etc.) & 1183 \\
\hline CC: Estar al día sobre las nuevas tecnologías de la información y la comunicación & 1417 \\
\hline
\end{tabular}

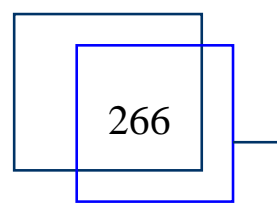

Cruz Pérez Pérez, Inmaculada López Francés y $M^{a}$ Josefa Sospedra Baeza 


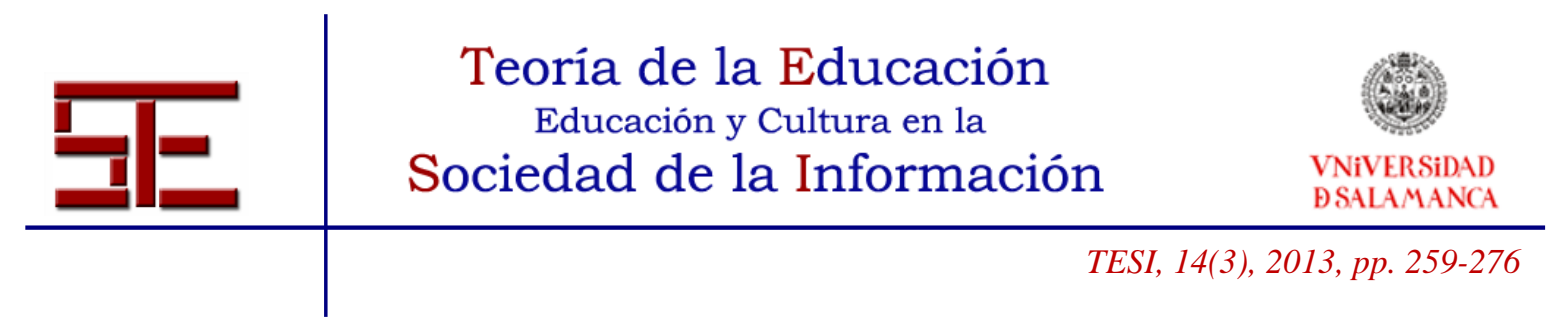

\begin{tabular}{|c|c|}
\hline $\begin{array}{l}\mathrm{CM} / \mathrm{T} \text { : Utilizar con eficacia las tecnologías de la información y la comunicación en las } \\
\text { actividades de enseñanza-aprendizaje }\end{array}$ & 1419 \\
\hline $\begin{array}{l}\text { CS/P: Participar en proyectos de innovación educativa que mejoren la calidad de la } \\
\text { enseñanza }\end{array}$ & 1448 \\
\hline $\mathrm{CM} / \mathrm{T}$ : Elaborar una guía de la asignatura que resulte útil y práctica para el alumnado & 1475 \\
\hline $\begin{array}{l}\text { CP: Tener buen conocimiento de uno mismo y una imagen realista de las propias } \\
\text { capacidades }\end{array}$ & 1486 \\
\hline $\begin{array}{l}\text { CS/P: Colaborar con otros profesores/as y trabajar en equipo para diseñar programas y } \\
\text { asignaturas coherentes y adaptados }\end{array}$ & 1503 \\
\hline CC: Conocer la metodología y las técnicas de investigación del área de conocimiento & 1505 \\
\hline CC: Dominar el vocabulario científico-técnico de la materia & 1507 \\
\hline $\begin{array}{l}\text { CC: Conocer los valores propios de la profesión docente y los que corresponden a la persona } \\
\text { como tal }\end{array}$ & 1528 \\
\hline $\begin{array}{l}\mathrm{CM} / \mathrm{T} \text { : Utilizar eficazmente las tutorías para ayudar y orientar al alumnado sobre las dudas y } \\
\text { cuestiones académicas que se le planteen }\end{array}$ & 1530 \\
\hline $\begin{array}{l}\text { CP: Asumir responsabilidades de organización y de coordinación docente necesarias para el } \\
\text { buen funcionamiento del sistema }\end{array}$ & 1533 \\
\hline $\begin{array}{l}\mathrm{CM} / \mathrm{T} \text { : Ser capaz de aplicar las estrategias y técnicas necesarias para resolver los conflictos } \\
\text { que puedan surgir en la clase }\end{array}$ & 1543 \\
\hline CM/T: Aplicar estrategias y técnicas que enseñen a los alumnos a trabajar en grupo & 1544 \\
\hline $\begin{array}{l}\text { CP: Saber tomar decisiones individualmente y ayudar a procesos colectivos de toma de } \\
\text { decisiones }\end{array}$ & 1549 \\
\hline CC: Conocer estrategias educativas innovadoras para mejorar la práctica educativa & 1561 \\
\hline CS/P: Mostrar sensibilidad hacia la interculturalidad y hacia la diversidad del alumnado & 1569 \\
\hline $\begin{array}{l}\text { CP: Tomar conciencia de que con la acción educativa, el profesor/a comparte y construye } \\
\text { valores con sus alumnos/as }\end{array}$ & 1589 \\
\hline $\begin{array}{l}\text { CM/T: Aplicar técnicas eficaces de evaluación que permitan conocer las competencias } \\
\text { adquiridas por el alumnado y mejoren el proceso de aprendizaje }\end{array}$ & 1599 \\
\hline $\begin{array}{l}\text { CS/P: Potenciar en el alumnado actitudes de participación y colaboración como miembros } \\
\text { activos de la comunidad educativa }\end{array}$ & 1600 \\
\hline $\begin{array}{l}\text { CP: Tener capacidad de relación y comunicación con los demás profesores y con el } \\
\text { alumnado }\end{array}$ & 1600 \\
\hline CP: Asumir la necesidad de formarse de un modo continuado & 1603 \\
\hline $\begin{array}{l}\text { CS/P: Diseñar estrategias didácticas y metodológicas que faciliten el proceso de enseñanza- } \\
\text { aprendizaje del alumnado. }\end{array}$ & 1613 \\
\hline $\begin{array}{l}\text { CM/T: Usar los resultados de la evaluación como elemento de mejora del aprendizaje del } \\
\text { alumnado, y no exclusivamente acreditativo }\end{array}$ & 1622 \\
\hline CC: Conocer ampliamente los contenidos científicos de la materia que imparte & 1626 \\
\hline $\begin{array}{l}\text { CP: Poseer equilibrio emocional y autocontrol suficientes para enfrentarse a las situaciones } \\
\text { y dificultades del proceso educativo }\end{array}$ & 1639 \\
\hline $\begin{array}{l}\text { CM/T: Ser capaz de preparar, seleccionar y construir actividades y materiales adecuados } \\
\text { para el trabajo en el aula }\end{array}$ & 1645 \\
\hline $\begin{array}{l}\text { CS/P: Ser capaz de reflexionar críticamente sobre la propia práctica docente, para introducir } \\
\text { elementos de cambio y mejora }\end{array}$ & 1653 \\
\hline $\begin{array}{l}\text { CC: Tener la formación pedagógica necesaria para dirigir el proceso de } \\
\text { enseñanza/aprendizaje }\end{array}$ & 1660 \\
\hline CC: Saber organizar y secuenciar adecuadamente los contenidos de aprendizaje & 1696 \\
\hline
\end{tabular}

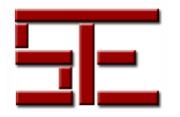

Cruz Pérez Pérez, Inmaculada López Francés y $M^{a}$ Josefa Sospedra Baeza 


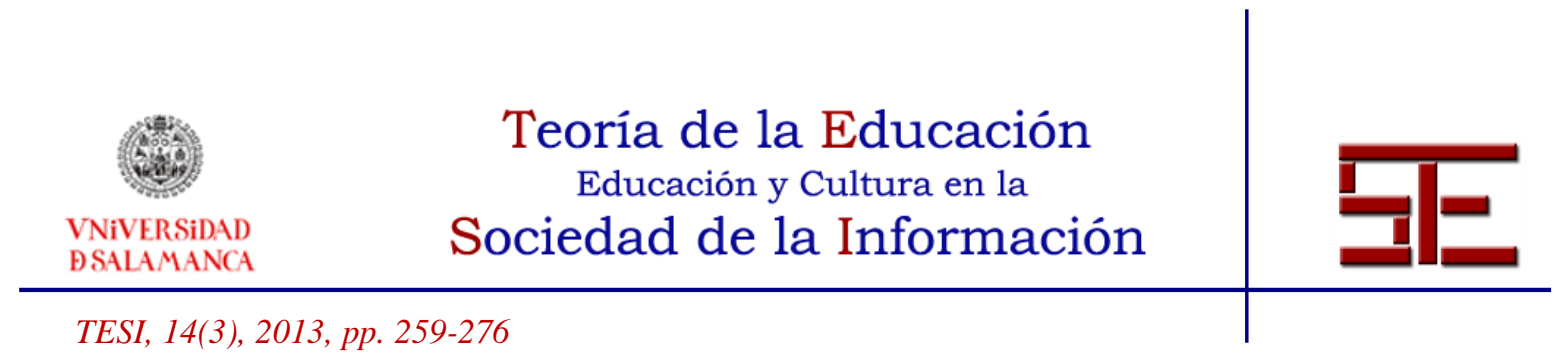

CP: Fomentar un clima relacional de aula basado en el respeto al otro y en la libertad de expresión, utilizando constantemente el diálogo y la comunicación

\subsubsection{Resultados globales por grupos de competencias}

Atendiendo a la valoración dada para cada una de las escalas (gráfico 1), la más valorada por los sujetos es la de Competencias Personales, seguida de Competencias Científicas. Las escalas Competencias Metodológicas/Técnicas y Competencias Sociales/Participativas obtienen una valoración muy similar.

\section{GRÁFICO 1. Valoración de las Escalas}

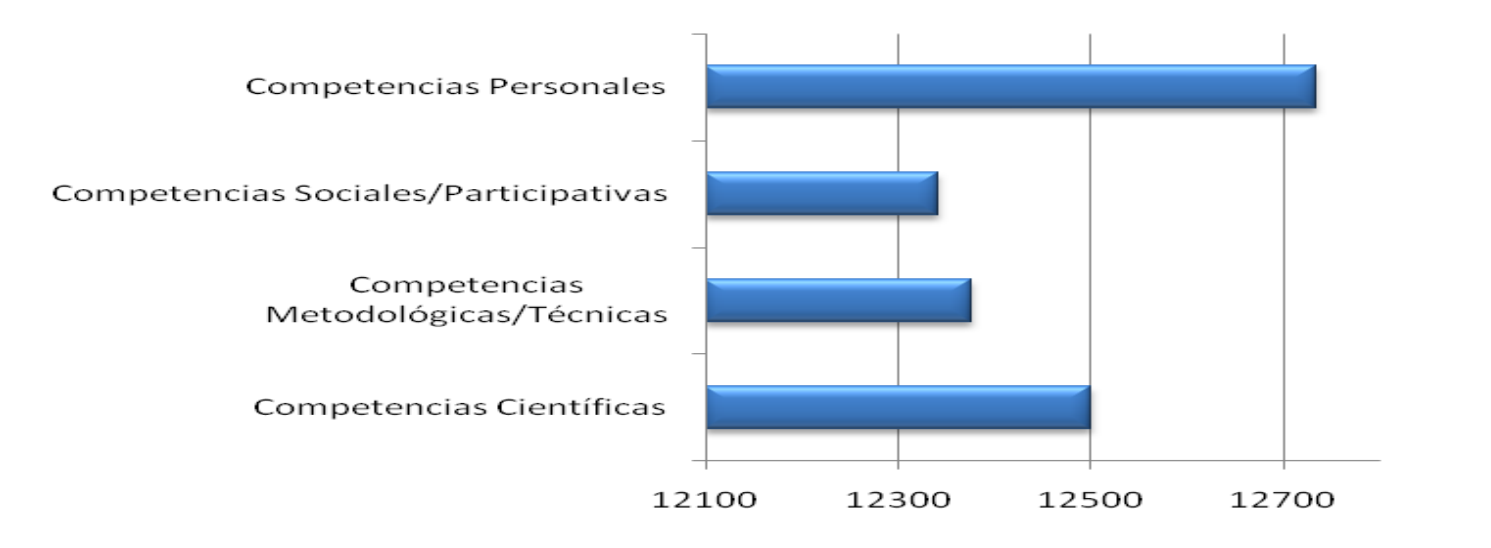

\subsubsection{Resultados de cada una de las escalas de competencias establecidas}

\section{- Competencias Científicas}

Considerando la valoración de los ítems que componen cada una de las escalas de competencias (gráfico 2), la competencia del grupo mejor valorada por los alumnos es "saber organizar y secuenciar adecuadamente los contenidos de aprendizaje", seguida de "tener formación pedagógica necesaria para dirigir el proceso de enseñanza/aprendizaje" y de "conocer ampliamente los contenidos científicos de la materia que se imparte", la menos valorada ha sido "estar al día sobre las nuevas tecnologías de la información y la comunicación”.

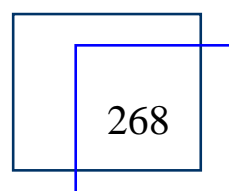

Cruz Pérez Pérez, Inmaculada López Francés y $M^{a}$ Josefa Sospedra Baeza 


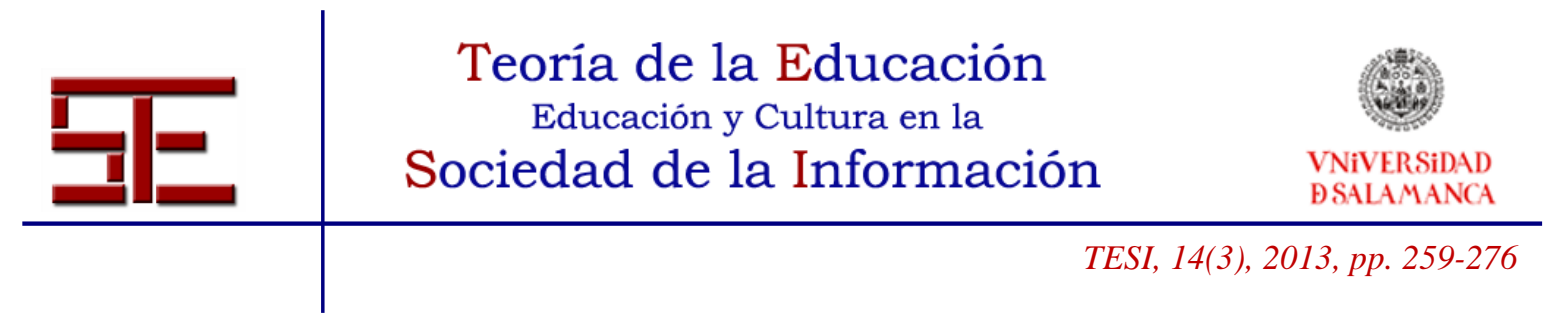

GRÁFICO 2. Valoración ítems de Competencias Científicas

\section{Competencias Científicas}

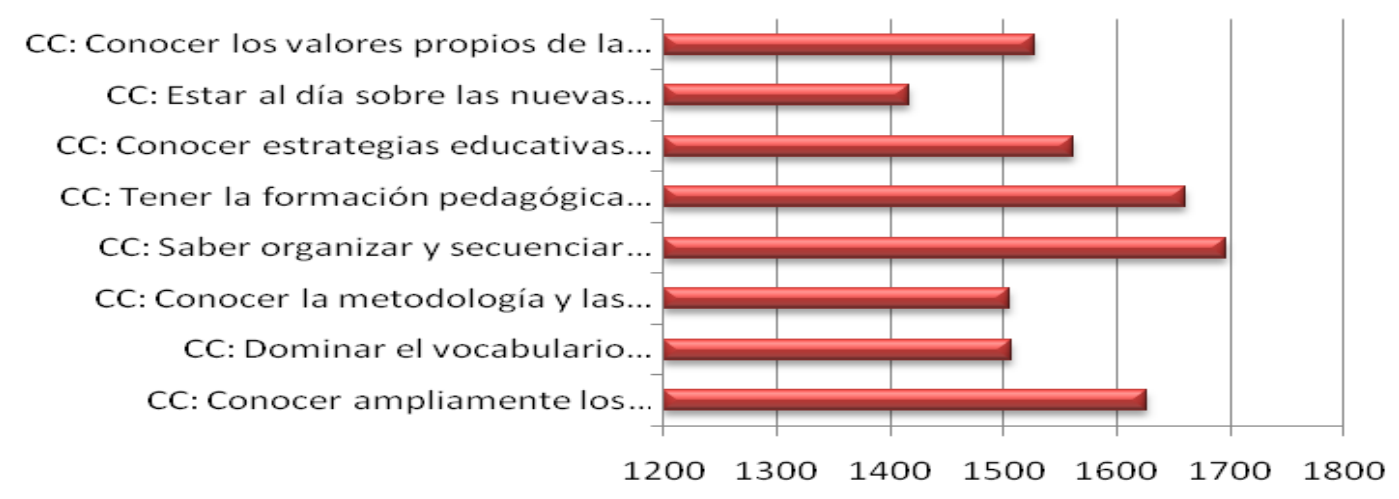

- Competencias Metodológicas/Técnicas

Por lo que respecta a las competencias metodológicas (gráfico 3), la mejor valorada es "ser capaz de preparar, seleccionar y construir actividades y materiales adecuados para el trabajo en el aula", seguida de "usar los resultados de la evaluación como elemento de mejora del aprendizaje del alumnado, y no exclusivamente acreditativo y de aplicar técnicas eficaces de evaluación", la menos valorada ha sido "utilizar con eficacia las tecnologías de la información y la comunicación en las actividades de enseñanza/aprendizaje".

\section{GRÁFICO 3. Valoración ítems de Competencias Metodológicas/Técnicas}

\section{Competencias Metodológicas/Técnicas}
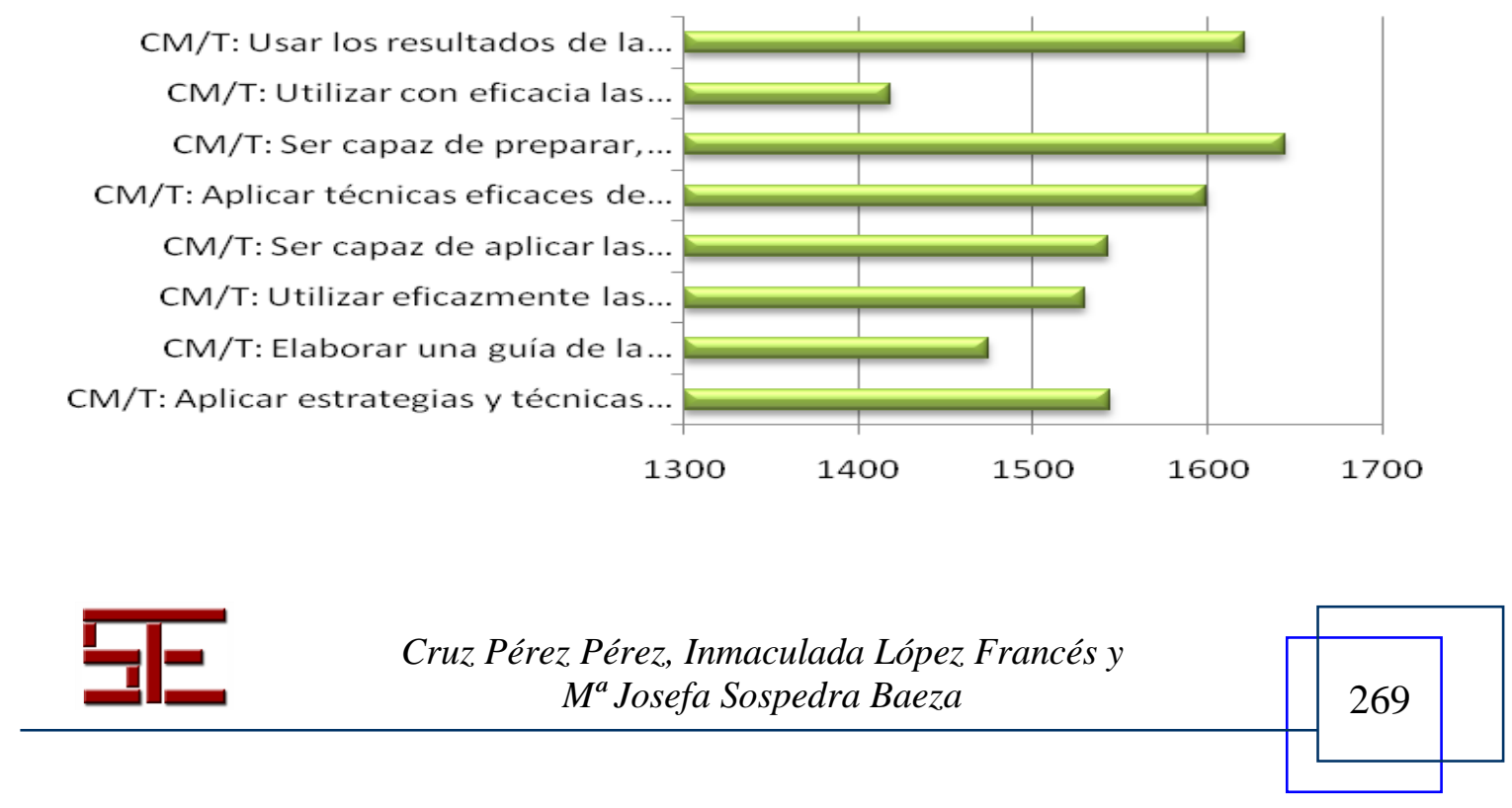


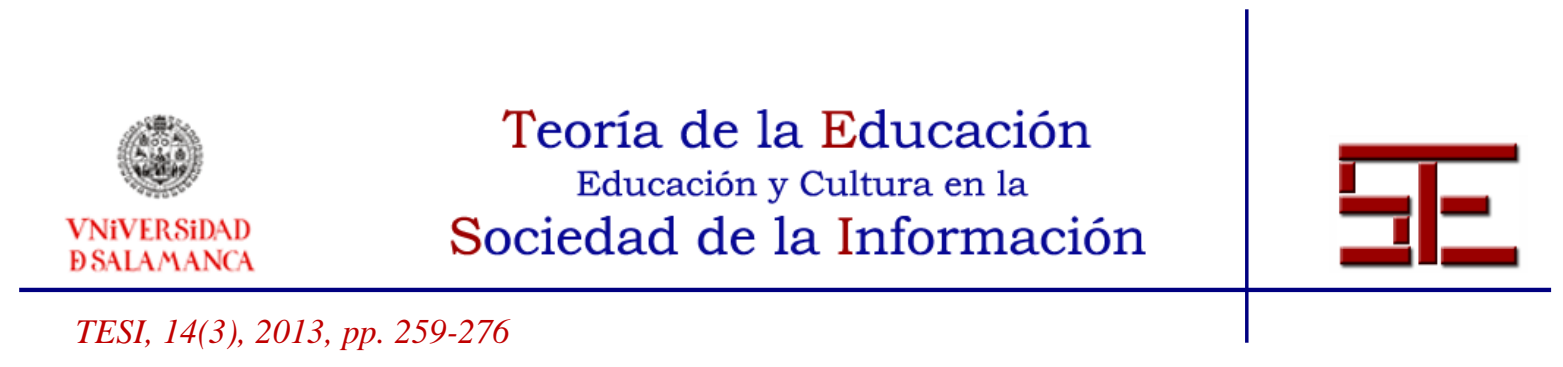

- Competencias sociales/participativas

Entre las competencias sociales/participativas (gráfico 4), la más valorada ha sido "ser correcto y respetuoso en el trato con el alumnado", seguida de "ser capaz de reflexionar críticamente sobre la propia práctica docente, para introducir elementos de cambio y mejora", "diseñar estrategias didácticas y metodológicas que faciliten el proceso de enseñanza-aprendizaje del alumnado" y "potenciar en el alumnado actitudes de participación y colaboración como miembros activos de la comunidad educativa". La menos valorada ha sido "mantener una imagen personal cuidada (vestuario, peluquería, etc.)".

GRÁFICO 4. Valoración ítems de Competencias Sociales/Participativas Competencias Sociales/Participativas

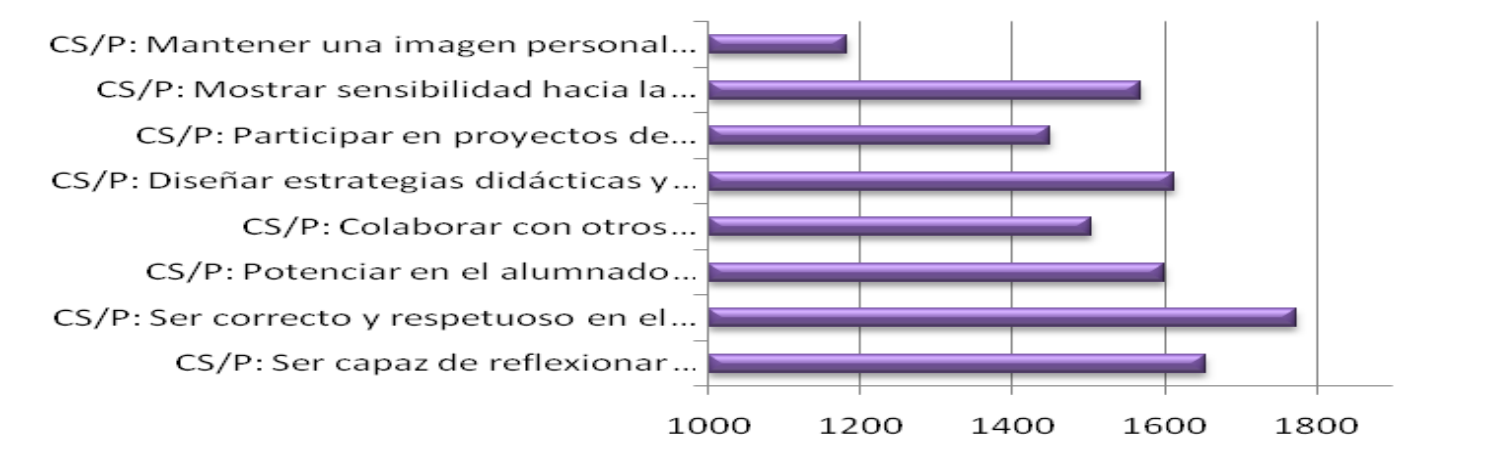

\section{- Competencias personales}

Por último, entre las competencias personales (CP), la más valorada ha sido "fomentar un clima relacional de aula basado en el respeto al otro y en la libertad de expresión, utilizando constantemente el diálogo y la comunicación" (gráfico 5), seguida de "poseer equilibrio emocional y autocontrol suficientes para enfrentarse a las situaciones $y$ dificultades del proceso educativo". La menos valorada ha sido "tener un buen conocimiento de uno mismo y una imagen realista de las propias capacidades".

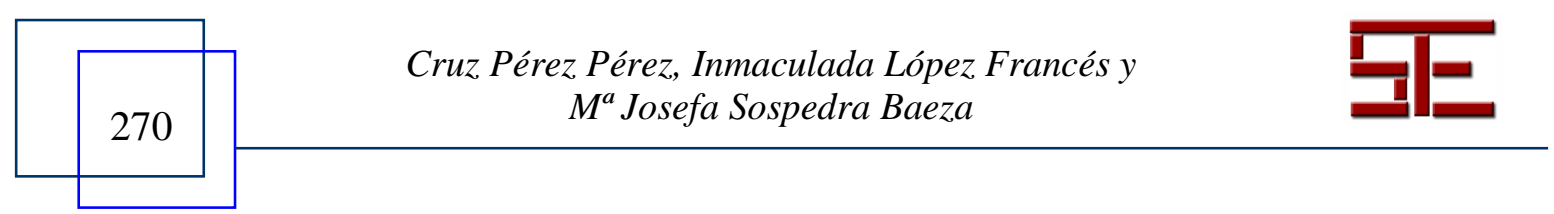




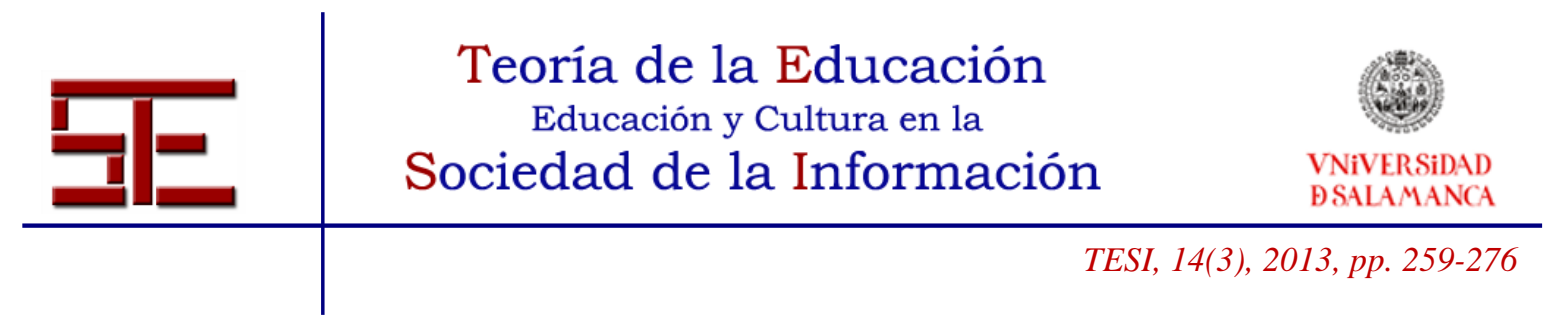

\section{GRÁFICO 5. Valoración ítems de Competencias Personales}

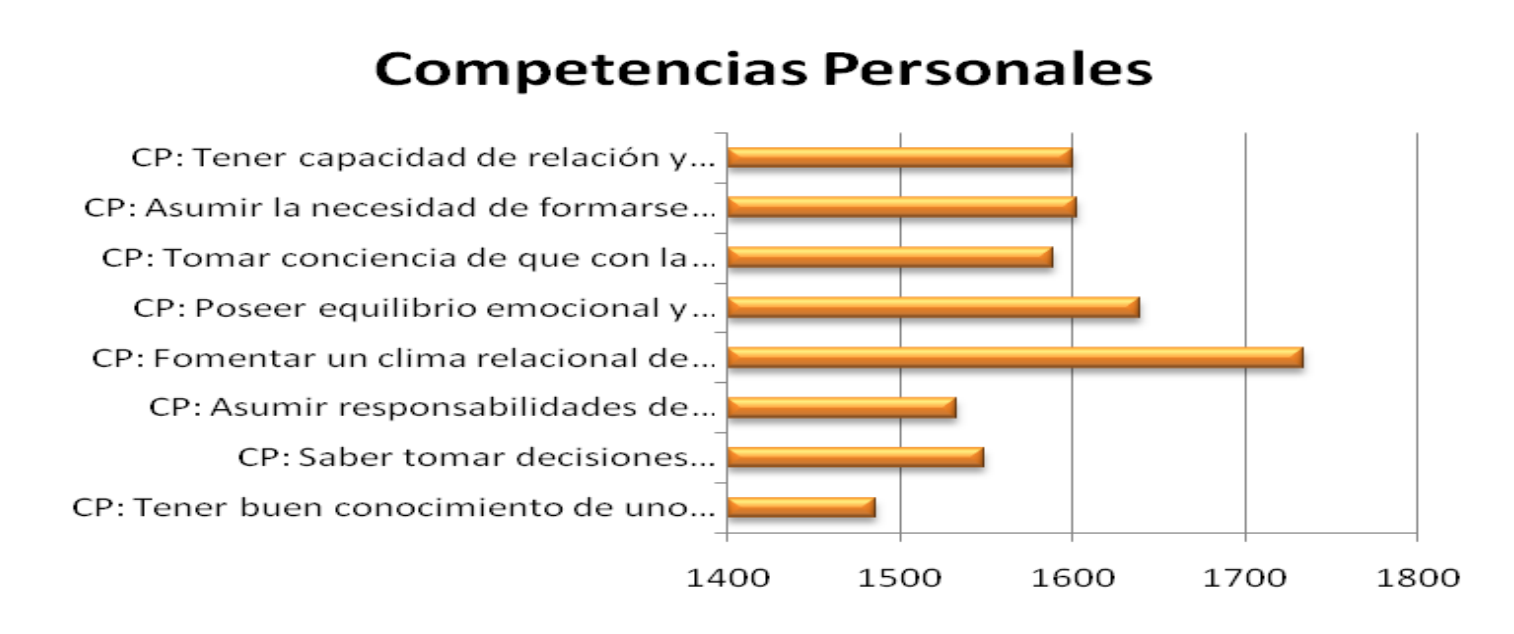

\subsubsection{Resultados obtenidos en función del género.}

También resulta interesante ver si existen diferencias significativas entre los chicos y las chicas a la hora de valorar las competencias del profesorado. Para comparar las valoraciones entre chicos y chicas en cada escala, la puntuación otorgada por los chicos y chicas a cada una de las competencias se ha normalizado para evitar el efecto del tamaño diferencial en ambos grupos $(72,8 \%$ de chicas y $27,2 \%$ de chicos) sobre la puntuación máxima de cada uno de ellos.

Tanto los chicos como las chicas valoran todas las competencias como importantes y muy importantes para el proceso de E/A (gráfico 6), pero las chicas dan valoraciones un poco más elevadas que los chicos a todas las competencias, a excepción de las competencias científicas que son valoradas como muy importantes tanto por los chicos como por las chicas, y se observa un patrón diferencial por lo que respecta a las competencias metodológicas/técnicas entre ambos grupos de alumnos. Las chicas consideran las $\mathrm{CP}$ las más importantes, seguidas de las $\mathrm{CC}$, de las $\mathrm{CM} / \mathrm{T}$ (aunque en todos los casos estás competencias se valoran como muy importantes) y las menos importantes según las chicas son las competencias CS/P.

En el caso de los chicos, las competencias más valoradas también son las $\mathrm{CP}$, seguidas de las CC (ambas valoradas como muy importantes), en tercer lugar consideran importantes las CS/P y en último lugar las CM/T.

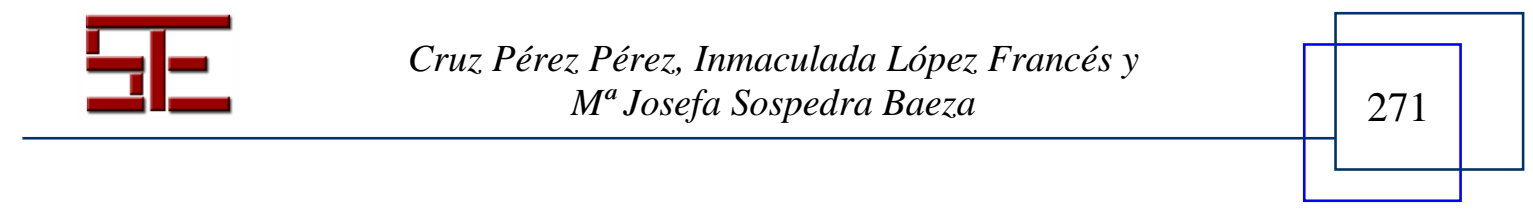



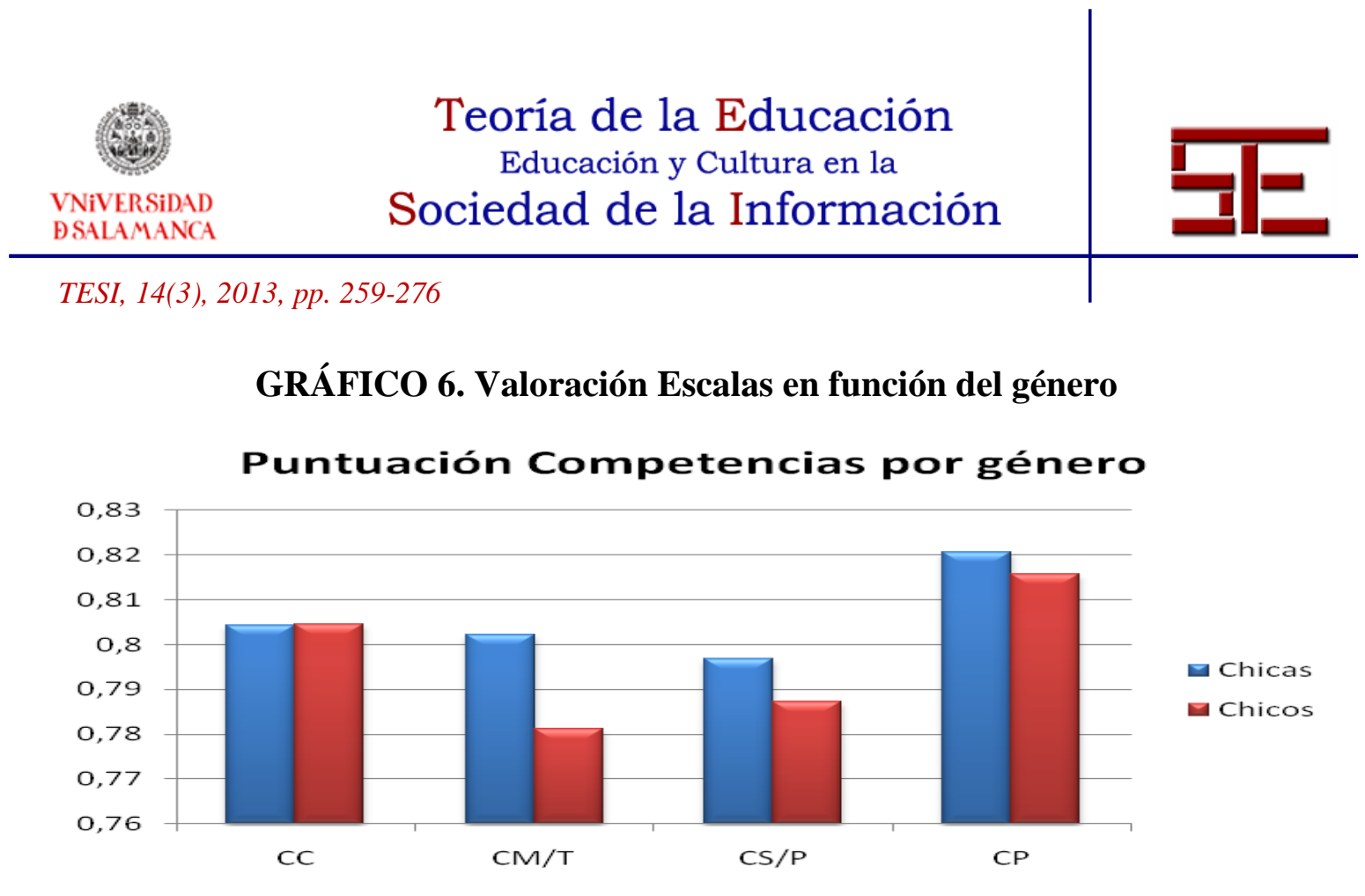

$\mathrm{Al}$ analizar las valoraciones otorgadas a cada uno de los ítems, independientemente de la escala, se obtienen los siguientes resultados:

Competencias más valoradas por las chicas:

1.- Ser correcto y respetuoso en el trato con el alumnado.

2.- Fomentar un clima relacional de aula basado en el respeto al otro y la libertad de expresión utilizando constantemente el diálogo y la comunicación.

3.- Saber organizar y secuenciar adecuadamente los contenidos de aprendizaje.

4.- Tener la formación pedagógica necesaria para dirigir el proceso de enseñanza/aprendizaje.

5.- Poseer equilibrio emocional y autocontrol suficientes para enfrentarse a las situaciones y dificultades del proceso educativo.

Competencias menos valoradas por las chicas:

1.- Mantener una imagen personal cuidada (vestuario, peluquería, etc.).

2.- Utilizar con eficacia las tecnologías de la información y la comunicación en las actividades de enseñanza-aprendizaje.

3.- Estar al día sobre las nuevas tecnologías de la información y la comunicación.

4.- Participar en proyectos de innovación educativa que mejoren la calidad de la enseñanza.

5.- Tener un buen conocimiento de uno mismo y una imagen realista de las propias capacidades.

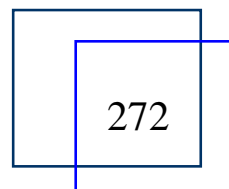

Cruz Pérez Pérez, Inmaculada López Francés y $M^{a}$ Josefa Sospedra Baeza 


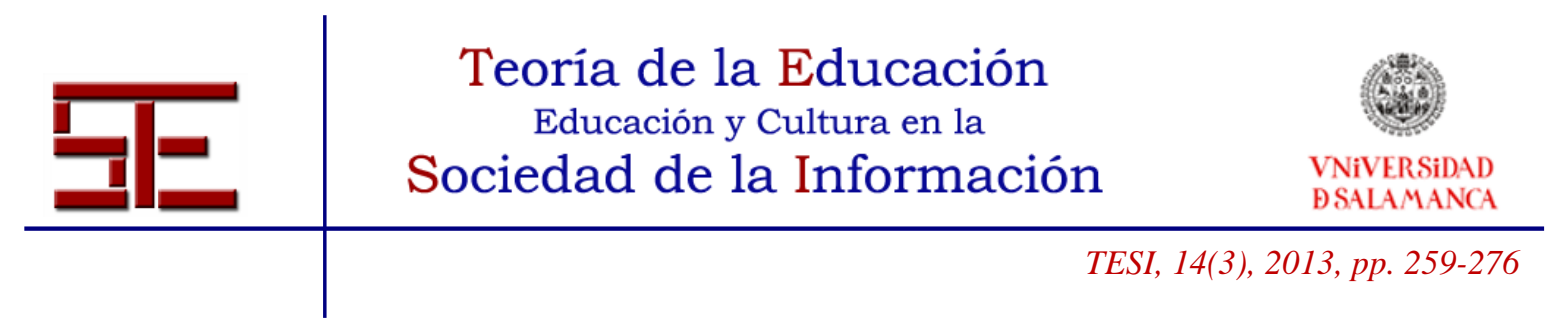

Competencias más valoradas por los chicos:

1.- Ser correcto y respetuoso en el trato con el alumnado.

2.- Fomentar un clima relacional de aula basado en el respeto al otro y en la libertad de expresión, utilizando constantemente el diálogo y la comunicación.

3.- Saber organizar y secuenciar adecuadamente los contenidos de aprendizaje.

4.- Ser capaz de reflexionar críticamente sobre la propia práctica docente, para introducir elementos de cambio y mejora.

5.- Conocer ampliamente los contenidos científicos de la materia que imparte.

Competencias menos valoradas por los chicos:

1.- Mantener una imagen personal cuidada (vestuario, peluquería, etc.).

2.- Estar al día sobre las nuevas tecnologías de la información y la comunicación.

3.- Utilizar con eficacia las tecnologías de la información y la comunicación en las actividades de enseñanza-aprendizaje.

4.- Elaborar una guía de la asignatura que resulte útil y práctica para el alumnado.

5.- Participar en proyectos de innovación educativa que mejoren la calidad de la enseñanza.

\section{CONCLUSIONES DE LA INVESTIGACIÓN}

Los datos obtenidos muestran cómo valoran los alumnos/as las competencias del profesorado para el proceso de enseñanza/aprendizaje. Son datos extraídos de una muestra importante compuesta por 389 alumnos y alumnas de las titulaciones de Ciencias Sociales y Jurídicas, y corroboran que las 32 competencias analizadas obtienen una alta valoración por parte del alumnado, sin que exista ninguna que la hayan considerado irrelevante para el ejercicio de la docencia. Este dato nos indica, tal y como ya quedó reflejado en el estudio piloto, que los ítems del cuestionario están bien seleccionados y son representativos del conjunto de conocimientos, habilidades, actitudes y destrezas que deben poseer los docentes para abordar el proceso de enseñanza/aprendizaje.

El segundo dato relevante para la acción educativa es que de los cuatro bloques de competencias, el alumnado considera que las competencias personales del profesorado son las más importantes para su proceso de enseñanza/aprendizaje (12.733 puntos), seguida de las competencias científicas (12.500 puntos). Las competencias metodológicas/técnicas (12.377 puntos) y las sociales participativas (12.341) obtienen puntuaciones muy parejas. Este dato, dentro de un contexto de la alta valoración otorgada a todas las competencias propuestas, nos indica que los factores personales y humanos del profesorado como la capacidad de relación y comunicación, los valores, el equilibrio emocional, el respeto al otro, la responsabilidad, saber tomar decisiones, el

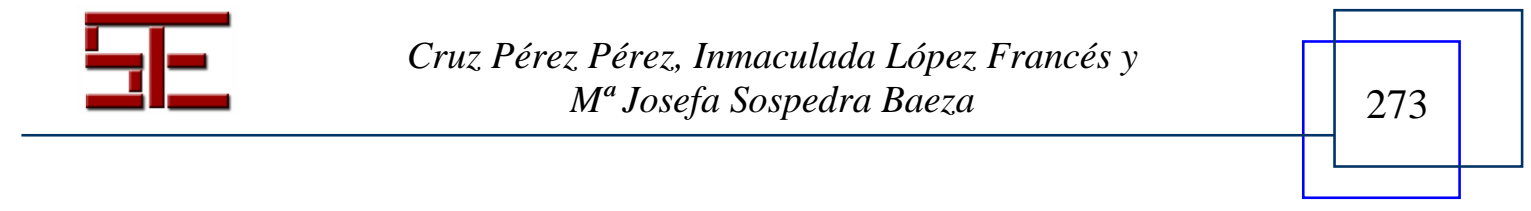




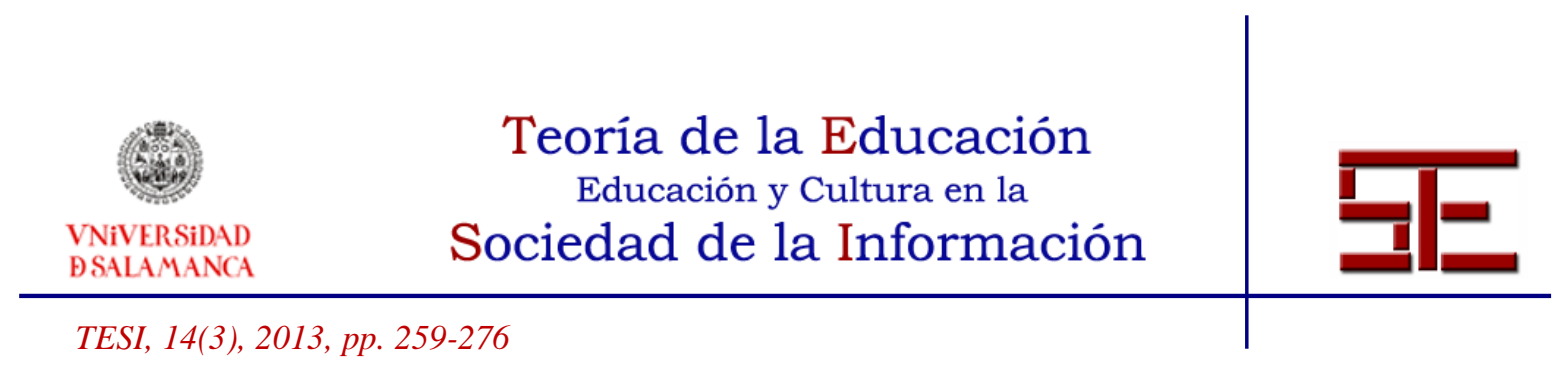

conocimiento de uno mismo, etc., son prioritarios para el alumnado, por encima incluso de la capacidad científica de los docentes.

El tercer dato a considerar, dentro de la valoración global de las competencias propuestas, es que las dos competencias más valoradas hacen referencia al trato correcto y respetuoso con el alumnado, así como a la creación de un clima de aula basado en el diálogo y la comunicación. Este dato es una constante que se repite en todas las titulaciones analizadas, con pequeñas variaciones. Le siguen tres competencias de carácter muy pedagógico como son "Saber organizar y secuenciar adecuadamente los contenidos de aprendizaje", "Tener la formación pedagógica necesaria para dirigir el proceso de enseñanza/aprendizaje" y "Ser capaz de reflexionar críticamente sobre la propia práctica docente, para introducir elementos de cambio y mejora".

Resulta significativo que la competencia "mantener una imagen personal cuidada..." aparezca como la menos valorada en todas las titulaciones (sólo en el máster de secundaria, grupo B aparece como la penúltima). También llama poderosamente la atención el hecho que las dos competencias referidas al conocimiento y uso didáctico de las tecnologías de la información y la comunicación aparecen en todas las titulaciones analizadas como de las menos valoradas, si bien es cierto que en un contexto de alta valoración de todas las competencias. Este dato coincide con los resultados de la investigación realizada en la titulación de Pedagogía durante el curso 2010-11 (Pérez y López, 2012).

Respecto a la prospectiva de la investigación, cabe señalar que en este momento se está aplicando el cuestionario en las ramas de Ciencias y de Ciencias de la Salud de la Universidad de Valencia, lo cual nos permitirá completar el estudio en los diferentes ámbitos de conocimiento de la UV, y establecer comparaciones y análisis entre los resultados de las diferentes titulaciones y áreas de conocimiento de una muestra representativa de todo el alumnado de la Universidad de Valencia. También se ha iniciado una línea de investigación en dos países diferentes: Cuba y México, en los que se está aplicando el cuestionario señalado. En Cuba se lleva a cabo en el Centro de Referencia para la Educación de Avanzada (CREA), del Instituto Superior Politécnico "José Antonio Echeverría" (CUJAE) de La Habana, y en México, en la UAEM (Universidad Autónoma del Estado de Morelos).

\section{REFERENCIAS}

Álvarez-Rojo, V. (2009). Perfiles docentes para el espacio europeo de educación superior (EEES) en el ámbito universitario español. Relieve. Revista electrónica de investigación y evaluación educativa, 15 (1), 1-18.

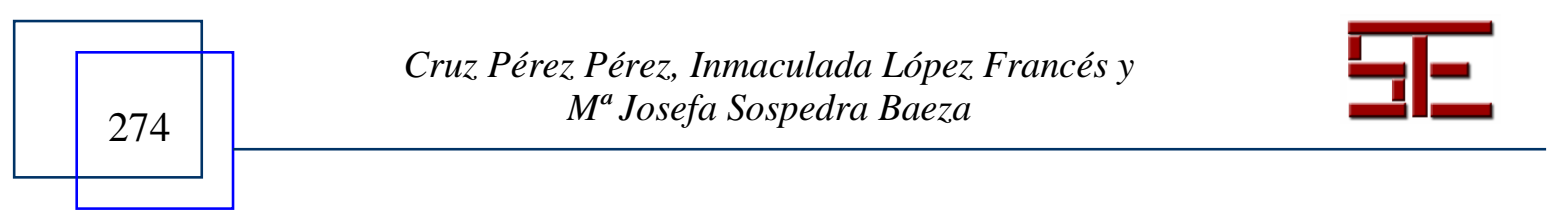




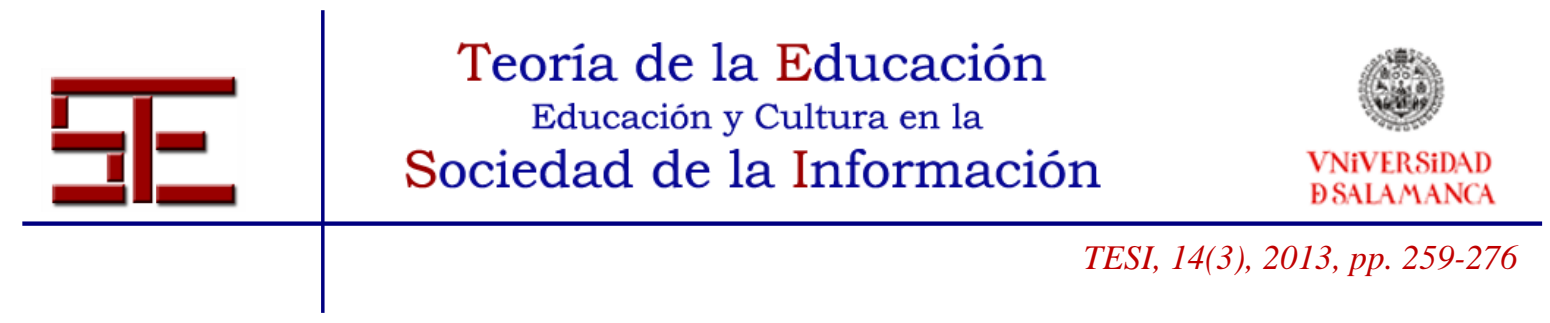

Cano, Ma E. (2008). La evaluación por competencias en la Educación Superior. Profesorado. Revista de curriculum y formación del profesorado, 12, (3), 1-16.

González, A. y otros (2011). Aprendizaje por competencias en la educación obligatoria. Valencia: Brief.

González, J. y Wagenaar, R. (2003). Tuning Educational Structures in Europe. Final Report - Phase One. Bilbao. Universidad de Deusto. Consultado el 13 de octubre en http://www.relint.deusto.es/TUNINGProject/index.htm.

Ion, G. y Cano E. (2012). La formación del profesorado universitario para la implementación de la evaluación por competencias. Educación S. XXI., 15.2, 249-270.

Le Boterf, G. (2000). La ingeniería de las competencias, Barcelona, Gestión 2000.

Pérez, C. y López, I. (2012). La percepción del alumnado sobre las competencias del profesorado en la titulación de Pedagogía de la Universidad de Valencia. Revista Iberoamericana de Educación, 59 (4), 1-9.

Rey, B. (2000). ¿Existen las competencias transversales?, Educar, 26, 9-17.

Roelofs, E. y Sanders, P. (2007). Towards a framework for assessing teacher competence. European Journal of Vocational Training, 40 (1), 123-139.

Sarramona, J. (2004). Las competencias básicas en la enseñanza obligatoria. Barcelona: CEAC.

Smith, K. S. y Simpson, R. D. (1995). Validating Teacher Competencies for Faculty members in Higher Education: A national study using the Delphi method. Innovative Higher Education, 19 (3), 223-234.

Tigelaar, E. H. y otros (2004). The development and validation of a framework for teaching competencies in Higher Education, Higher Education: the International Journal of Higher Education and Educational Planning, 48 (2), 253-268).

Tribó, G. (2008). El nuevo perfil profesional de los profesores de Secundaria. Educación XXI, 11, pp.183-209.

Zabala, A. y Arnau, L. (2007). Cómo aprender y enseñar competencias: 11 ideas clave. Barcelona: Graó.

Zabalza, M. A. (2003). Competencias docentes del profesorado universitario. Calidady desarrollo profesional. Madrid: Narcea.

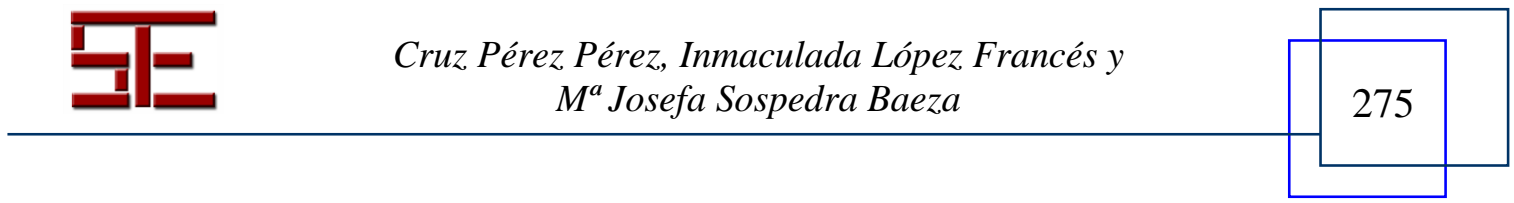




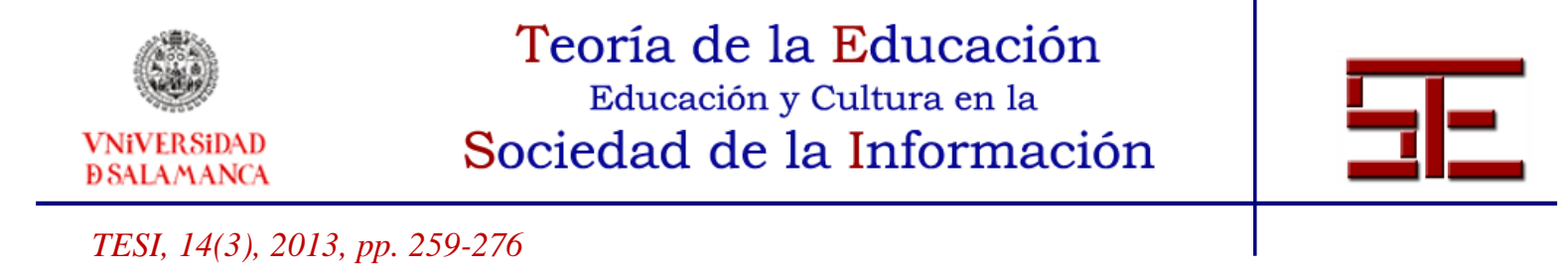

\section{NOTAS}

${ }^{1}$ El siguiente trabajo forma parte de una investigación más amplia sobre las competencias del profesorado de la Universidad de Valencia, que se está llevando a cabo desde el curso 2008/09 por el grupo de investigación de la titulación de Pedagogía del que forman parte los autores de este trabajo, en las diferentes áreas de conocimiento de la Universidad de Valencia, y que está financiada, dentro del programa “Docinvest” por la Unitat D'Innovació Educativa de la Universitat de Valencia.

${ }^{2}$ Los cuatro saberes definidos por Delors en su informe, bien pueden ser considerados como competencias, pues son aprendizajes complejos, se aprenden en un contexto a través de experiencias y posibilidades de ejercitación en las que se deben solucionar problemas, son observables en desempeños y requieren de los procesos de aprendizaje de toda la vida para alcanzar su dominio. Sin embargo estos cuatro saberes también pueden ser considerados objetivos generales de la educación en la medida que orientan la acción pedagógica y de ser alcanzados por los aprendices se constituyen en fuente de realización personal y social.

Para citar el presente artículo puede utilizar la siguiente referencia:

Pérez Pérez, C., López Francés, F. y Sospedra Baeza, M. J. (2013). La percepción del alumnado sobre las competencias docentes del profesorado de la rama de ciencias sociales y jurídicas de la Universitat de València. Revista Teoría de la Educación: Educación y Cultura en la Sociedad de la Información. 14(3), 259-276 [Fecha de consulta: $\mathrm{dd} / \mathrm{mm} / \mathrm{aaaa}]$.

http://campus.usal.es/ revistas_trabajo/index.php/revistatesi/article/view/11360/11777

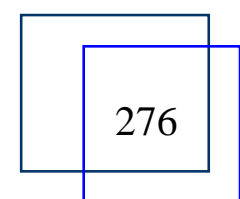

Cruz Pérez Pérez, Inmaculada López Francés y $M^{a}$ Josefa Sospedra Baeza 